\title{
Sasja Samovar of Isaak Babel achterna
}

\author{
William Peynsaert
}

\section{Voorwoord}

In Van Mensen en Dingen verkennen we graag alle aspecten van de volkscultuur en overschrijden daarbij af en toe de Vlaamse grenzen. In deze korte bijdrage komt het literaire aspect van de volkscultuur aan bod. We bekijken namelijk een kortverhaal van William Peynsaert, waarin hij de denk- en leefwereld schetst van een eenvoudige Russische soldaat. We hebben een verklarende woordenlijst en een begeleidende omkadering van dit verhaal toegevoegd. Veel leesplezier!

Elise Vos, voor de redactie.

\section{Sasja Samovar}

In de zomer van 1941 werkte ik als dagloner in een sovchoz (1). Ik was pas 19 geworden. We verbouwden gierst. Om eerlijk te zijn, was het daar één en al armoede, maar ik kan niet zeggen dat we het echt slecht hadden. Van luxe was er natuurlijk geen sprake. Maar dat gaf niet. We waren in de gezonde buitenlucht, er was elke dag verse melk, de meisjes waren knap en het werk, nou, dat viel best mee. Daar raakte je aan gewend.

Die zomer in juni dus, vielen de Duitsers binnen. Iedereen in paniek. Volledige chaos. Irina, de buurvrouw, kwam haar huis niet meer uit. Zat heel de tijd te bidden. Ze dacht, geloof ik, dat de Duitsers het speciaal op haar gemunt hadden. Ik werd opgeroepen. Mijn moeder in tranen. Vader was toen al lang dood, bezweken aan zijn ouwe wonde. Hadden de Witten (2) hem nog gelapt. Niet dat hij zelf een Rooie was. Nee, 


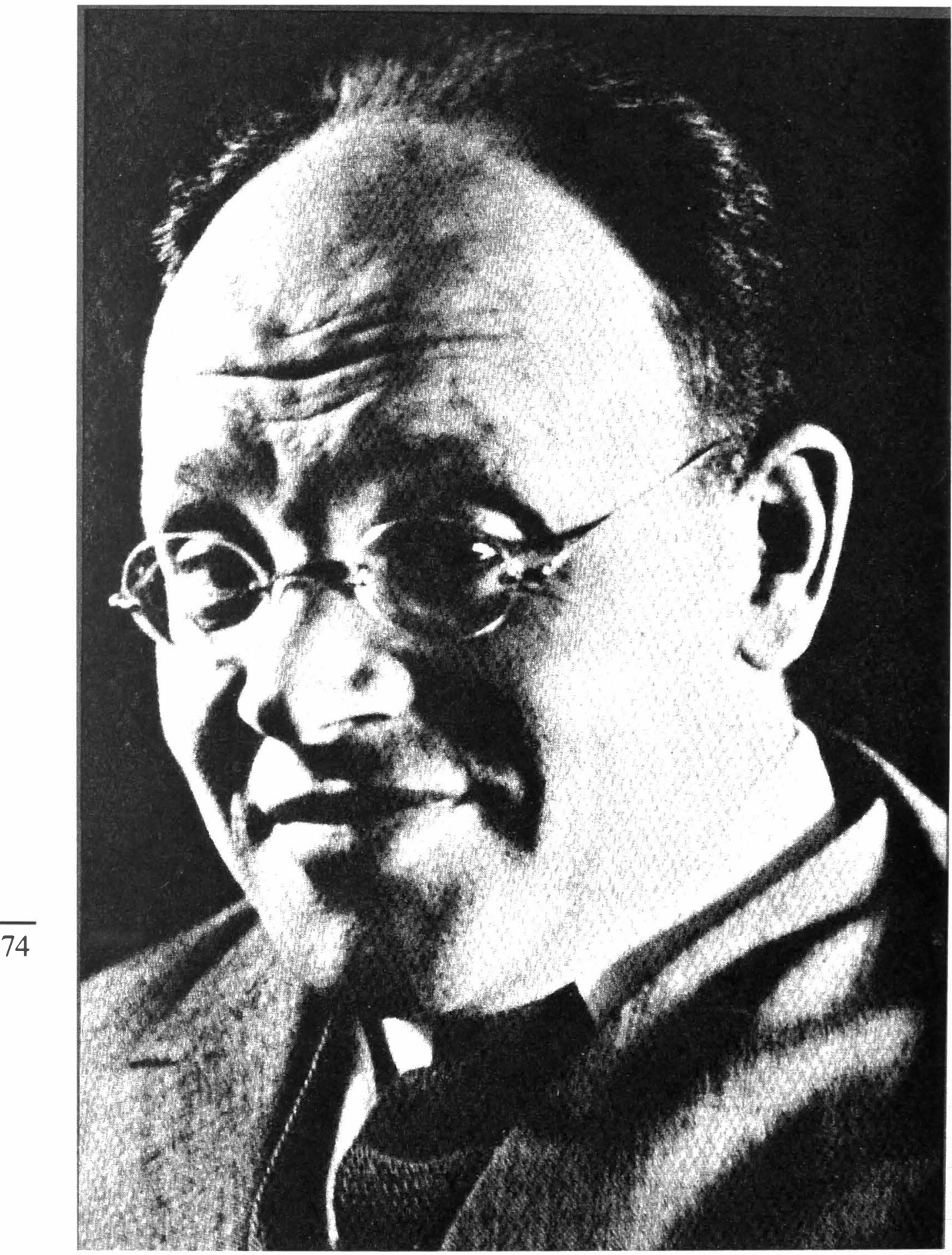

Isaak Babel 
gewoon, omdat hij niet wilde zeggen waar hij de patatten verstopt had. Ze lieten hem achter in onze schuur om te sterven. Bloedde als een rund. Maar bleef wel lang genoeg leven om mijn moeder te trouwen. Het hele dorp verklaarde haar voor gek, trouwen met Sasja Samovar (3). Je moest wel kierewiet zijn. Maar ze deed het en toen kwam ik, Joeri, de zoon van Sasja Samovar. Pas negentien en opgeroepen voor het front. Moeder stopte mij brood toe en zelfs een flink stuk worst, kruidkoeken en natuurlijk een voorraadje vodka, alles in een zakdoek gewikkeld. Dat is een heleboel voor een vrouw die zich verwarmde met het verbranden van mest en de koeien 's nachts in huis haalde, om het een beetje warm te hebben. Nou, ik kuste mijn grienende moeder vaarwel, zo op het voorhoofd, en gaf daama mijn zuster een klap om d'r oren, omdat ze mijn overlevingskansen als onbestaande inschatte. Heel moeilijk karakter, die zus van mij. En wat een taaltje! Zegt ze de ochtend dat ik vertrek tegen me - ik heb mijn ogen nog niet half open -, "Joeri, onnozel stuk vreten dat je bent, jij laat je als de eerste de beste sukkel lek schieten door zo'n vlezige, pafferige Duister. Let op mijn woorden. Als ik jou was, ging ik maar gauw op de loop, de bossen in, want van het front kom je niet levend terug. Niet dat het mij wat kan schelen." Maar toen ik dus in het gelid ging staan met de andere jongens van het dorp, toen pinkte ze toch een traan weg. Dan toch een sikkepit gevoel, dat sekreet.

Daarna was het marcheren en uitgekafferd worden en marcheren en uitgekafferd worden. Tot we op het station aankwamen en de trein op konden. Een hele belevenis, die trein. Haalde nauwelijks snelheid, stopte elk uur zonder duidelijke reden en onze officieren maar vloeken. Ik dacht er het mijne van, smikkelde de worst op en merkte tot mijn grote ontgoocheling dat ik de kruidkoeken al kwijt was. Geritst of domweg verloren. Wie zal het zeggen? Ik had al een aardige slok op. Tja, ik zag niet elke dag wodka. Ik voelde de warmte van de alcohol door me heen stromen en ging pitten. Geslapen dat ik heb! Die hele reis. Ik was een vaste slaper. Een heus voordeel, zo in oorlogstijd. Want je zou het niet denken, op foto en in de boekjes lijkt het altijd een heel avontuur, maar vaak is het gewoon echt een saaie boel, zo'n oorlog. Dan heb je niks om handen, tenzij ergens gaan scharrelen om je magere rantsoentje wat aan te vullen of kaarten, maar ik deed geen van beide. Als ik wat te eten vond, was er altijd wel een slimmerik die het mij op een of andere manier wist te ontfutselen. En wat het kaarten betreft, geldt al net hetzelfde, want ze 
speelden voor geld en waar moest ik verdorie geld vandaan halen? Ach, ik mocht niet klagen. We kregen elke dag havermoutpap, onze bevoorradingschef had havermout te over. Had hij liggen bedisselen met een hoge piet -althans dat werd verteld - en zo zaten wij dus goed. Heel die oorlog, havermoutpap. Tot het onze oren uitkwam. Maar mij deerde het niet, want havermoutpap is nu toevallig mijn lievelingskostje. Op de sovchoz kregen we dat hooguit één keer in de maand te zien, dus ik had het best naar mijn zin, zo bij de infanterie. Dat is knap veel stappen, want een trein heb ik na die eerste drie weken niet meer van binnen gezien.

Nee, mijnheer, stappen, helemaal tot aan de Oder, tot ze mij dan toch te pakken kregen, die Duitsers. Mijn zus kreeg geen gelijk. Het was een wondje van niks, een echte "prijswinnaar", zei de arts. Een prijs heb ik nooit gekregen en toen ik naar huis mocht, heb ik er maar niet naar geïnformeerd. In die tijd moest je oppassen met wat je zei. Want voor één fout woord, kon je heibel hebben. Dan werd je ingedeeld bij een strafcompagnie. Kon je gelijk vooruit gaan als ze dachten dat er ergens mijnen lagen en mijnen lagen er altijd wel, die lieten de Duitsers achter als een paard zijn vijgen. Heel nauwgezette, methodische kereltjes, die Duitsers, maar we hebben ze er wel flink van langs gegeven. Niet in het begin. Toen ging het andersom. Dat kwam omdat zij eerst begonnen waren. Wat een idee om zoiets te gaan doen in hartje zomer! Pokkewarm was het. Als je twee uur zonder water zat, konden ze je wel opvegen. En elke dag vroeg op, natuurlijk, en marcheren. De eerste tijd vooral de verkeerde kant op, richting Moskou. Kregen onze officieren het bepaald van op hun zenuwen. Heb ik nooit goed gesnapt. Vechten is toch vechten? In Moskou al net hetzelfde als in Kiev, Charkov of Rostov-aan-de-Don. Of zie ik dat verkeerd? Best, ik marcheerde dus, deed wat me gezegd werd. Schieten op alles wat beweegt. Kon niet duidelijker. Bewoog er wat, knallen maar. Bleek dat ik verdomd aardig uit de voeten kon met een geweer. Neem nu, bijvoorbeeld, als er verkenners om ons heen slopen. Heel vervelend, die verkenners. Kwamen alles in de gaten houden, gingen in het gras op hun gemak liggen loeren, krabbelden in de rapte een briefje naar generaal zus of zo en voor je het wist, had je drie regimenten Duitsers op je dak en eerst nog een aardige lading lood van hun artillerie op je dinges. En als het even helemaal tegenzat, kwam er zo een Messcherschmidt overvliegen; dan kon je het negen van de tien keer wel schudden. Dus als er zo weer eens van 
die verkenners in de buurt waren, dan zei onze pelotonscommandant: "Dat is een klusje voor Joerotsjka. Haal Joerotsjka maar, die paft ze wel onder de zoden." En toen haalden ze mij erbij en dan joeg ik ze een kogel in de bast. Een eitje. Leek een beetje op eekhoorns schieten. Deden we vaak bij ons thuis. Alleen hadden deze eekhoorns zelf ook geweren. Deerde niet, wat mij betreft. Huppekee en weg met die geniepige ratten. Niet dat ik persoonlijk wat tegen Duitsers had. Ik heb nooit een Duitser gekend. Dus misschien zijn het wel heel toffe kerels. Maar in de krant stond al vast van niet en op de pamfletten ook al niet. Geen idee. Wat ik wel weet, is dat telkens de pelotonscommandant mij liet halen en ik de bewegende stippen die hij aanwees met de benen in de lucht deed vliegen, ik een flinke scheut vodka kreeg. Knapte je vreselijk van op. Zeker in de winter, want het bleef natuurlijk geen zomer.

Dus zo ging het er bij ons aan toe; veel marcheren, elke dag havermoutpap en af en toe een extra scheutje vodka. En toen kwam Vadim bij ons. Even oud als ik, maar wel een slimme kerel, die Vadim. Had op de unief gezeten, maar zat nu vrijwillig bij ons. Sympathiekste gast in heel het regiment en vertellen dat-ie kon. Over eender wat. Wist overal wel wat over te zeggen. Een hele aanwinst. Iedereen hing aan zijn lippen. Ik nog het meest van al. Een gedichten dat die voordroeg! Van Poesjkin (4)! Van Lermontov (5)! En nog een dozijn anderen waar je nooit van gehoord hebt. Nou, die Vadim, die werd mijn maatje. Gingen we winterkwartieren, hokten we samen. Alles deelden we. Ik mijn extraatjes vodka, hij de pakketjes die zijn moeder hem van thuis toestuurde. Die mama van Vadim was een hele lieve. Schreef ze hem een brief, dan deed ze mij altijd de groeten. Vond het opperbest dat wij zo goed op elkaar pasten. Dat deden we ook. Onafscheidelijk waren we. Ik leerde hem hoe hij een geweerloop moest invetten, hoe je je voeten kon inwikkelen tegen de koude en hij leerde mij over de sterren, over verre landen met van die vreemde volken met rare gewoontes en meer van dat. Bij ons in het regiment noemden ze ons Houtenkop en Wijsneus. Wij twee. Altijd samen. Reuzeleuke tijd. Tot ze Vadim overplaatsten. Strafcompagnie. Bij de politieke afdeling hadden ze te horen gekregen van zijn voordrachten en bij de politieken daar waren ze niet zo kunstminnend. Gedichten, nee, da"s verdacht. Dus overplaatsing. Niet erg. Nog niet erg. Brieven schrijven kan altijd nog en na de oorlog, na de oorlog zoeken we elkaar op, vieren de goede afloop en passen weer net zo goed op elkaar als nu. 
Ik gaf hem mijn mes als afscheidscadeau. Goed mes was dat, raakte je zelfs mee door het broodrantsoen en iedereen weet hoe hard dat was. Hij gaf mij een tekening. Tekenen kon hij ook en hoe! Pracht van een tekening was dat. Hij en ik samen aan tafel en zijn moeder had pannenkoeken gebakken. Geweldig cadeau, alleen raakte ik het kwijt in het veldhospitaal. Daar jatten ze alles van je, de leperds. Vadim heb ik niet meer weer gezien. Ik kreeg nog één brief. Daarna niks meer. Twee maand stilte, drie maand en nog langer. Tot Sergej op een dag naar me toekomt. Sergej was een jongen van bij ons in het dorp. Slecht karakter, maar ik had medelijden met hem, omdat ik wist dat hij er thuis steeds zo van langs kreeg. Dan zat hij te snikken achter het kippenhok en joeg iedereen weg die in zijn buurt kwam om hem te troosten. Die komt dus op mij af. Heel vrolijk. "Hé, Joerotsjka, kerel, hebben wij nieuws voor jou! Vadim, weet je wel, mijnheer de poëet, Aleksandr Sergejevitsj (6) uit de doden opgestaan, nou, die is nu wel mooi de pijp uit. En weet je wat ironisch is? Die makker van jou is als een samovar zijn kist ingegaan, ja, hebben ze hem de armen en benen van het lijf geknald, helemaal moes was-ie. Een samovar, net als je pa, hé, Joerotsjka, die goeie ouwe Sasja Samovar."

Toen ik Sergej op de grond geslagen had, droogde ik mijn vochtige vuisten aan mijn hemd. Vochtig, eerst van het bloed en daarna van de tranen. 


\section{Verklarende woordenlijst}

(1) Sovchoz: sovjetstaatsbedrijf, dat voornamelijk landbouwproducten verwerkte. (DETREZ, (R.). Rusland; een geschiedenis. Antwerpen, Houtekiet, 2008, p. 328)

(2) De Witten: tegenstanders van de Roden of Bolsjewieken in de Russische Burgeroorlog (1917-1921). (WAEGEMANS, (E.). Geschiedenis van de Russische literatuur; Sinds de tijd van Peter de Grote. Gent, Scoop, 1999, p. 462)

(3) Sasja Samovar: Sasja is het verkleinwoord voor de naam Aleksandr. Een dergelijke aanspreekvorm wordt doorgaans enkel gebruikt onder vrienden. Een samovar is een Russisch toestel om thee te zetten.

(4) Poesjkin: beroemde Russische schrijver uit de 19de eeuw.

(5) Lermontov: beroemde Russische schrijver uit de 19de eeuw.

(6) Aleksandr Sergejevitsj: voornaam en vadersnaam van Poesjkin. De Russen hebben doorgaans drie namen: een voornaam, vadersnaam of patroniem (afgeleid van de voornaam van de vader) en de familienaam.

Elise Vos, voor de redactie. 


\section{Isaak Babel achterna}

William Peynsaert schetst in zijn kortverhaal een eenvoudige held. Hij heeft een goede inborst: hij sluit vriendschappen en is met weinig tevreden. Hij gehoorzaamt blind de autoriteiten, stelt geen vragen en is goed in wat hij doet, al is het het neerschieten van mensen, tegen wie hij eigenlijk niet echt iets heeft. Daarmee voldoet hij aan bepaalde vereisten van de nieuwe Sovjetmens: hij is van eenvoudige komaf, gehoorzaamt zonder vragen en bouwt op deze manier mee aan het toekomstige socialistische arbeidersparadijs. Hij heeft immers op een sovchoz gewerkt voor de Grote Vaderlandse Oorlog. Peynsaert benadrukt de eenvoudige geest van zijn hoofdpersonage door het behoud en zelfs het in de verf zetten van zijn eenvoudige taalgebruik Toch durft hij wel een kritische noot te laten horen; namelijk dat er armoede was in de sovchozen. Dergelijke zaken uitspreken was gevaarlijk in de stalinistische tijden.

Peynsaerts kortverhaal doet sterk denken aan Isaak Babels oeuvre. Babel nam een vooraanstaande plaats in de Sovjetliteratuur in, maar werd in 1940 geëxecuteerd. Hij was een Russisch-joodse schrijver, die een ziekelijke belangstelling voor wreedheid aan de dag legde en dit in zijn verhalen liet doorschemeren. Zijn verhalencyclus Rode Ruiterij (1923-1924) vertelt over het primitieve geweld van de kozakken.

80 Babels helden moorden, roven, verkrachten, vloeken en slaan obscene taal uit. Het gaat om tragische, nachtmerrieachtige, wrede verhalen. Toch komen er ook poëtische passages in voor, die in scherp contrast staan met de wrede beelden. Hét genre van Babel is het korte verhaal, gepointeerde schetsen die meestal één voorval uitwerken met een verrassend slot. Hij hanteert in zijn schrijven een uiterste beknoptheid en gebruikt veel hyperbolen. Dit zijn twee aspecten die Peynsaert eveneens tracht na te streven met korte elliptische zinnen en krachtige zinsneden die hij uit de mond van zijn personages laat komen. (1)

Babel schreef een groot deel van zijn verhalen in de eerste persoon, 
ook een kenmerk dat Peynsaert aanhoudt. Zijn verhalen zijn doorspekt met autobiografische details. De beschrijving van bruut geweld, heel typerend voor Babels werk, wordt in dit kortverhaal ook door Peynsaert overgenomen. Babels moordende helden hebben geen medegevoel met hun slachtoffers, maar zijn anderzijds helemaal niet sadistisch. De held van onze Vlaamse auteur heeft dezelfde karaktertrekken. Babels korte verhalen tellen vaak niet meer dan twee of drie pagina's, net als die van Peynsaert. De metaforen en vergelijkingen van beiden zijn verrassend, beeldend en concreet. (2)

Elise Vos, voor de redactie.

(1) WAEGEMANS, (E.). Geschiedenis van de Russische literatuur; Sinds de tijd van Peter de Grote. Gent, Scoop, 1999, p. 259-261.

(2) WESTSTEIJN, (W.). Russische literatuur.Amsterdam, J. M. Meulenhoff, 2004, p. 278-281 